\title{
Total body water, electrolyte and thermoregulatory responses to ad libitum water replacement using two different water delivery systems during a $19 \mathrm{~km}$ route-march
}

\author{
Nolte, Heinrich $\mathrm{W}^{1^{*}}$, Nolte, $\mathrm{Kim}^{2}$, van der Meulen Julia ${ }^{1}$ \\ 11ERGOnomics TECHnologies, Research and Development, Armscor, Pretoria, South Africa; and \\ ${ }^{2}$ Division of Biokinetics and Sport Science, Department of Physiology, University of Pretoria, Pretoria, \\ South Africa.
}

*Address correspondence to Heinrich W. Nolte, heinrich@ergotech.co.za

\begin{abstract}
Hands-free hydration systems are often advocated for improved hydration and performance in military populations. The aim was to assess whether such systems indeed result in improved hydration in exercising soldiers. Subjects were required to complete a route-march while consuming water ad libitum from either a hydration bladder (BG) or traditional canteen (CG). Water intakes of $538 \mathrm{~mL} \mathrm{~h}^{-1}$ (BG) and $533 \mathrm{~mL}$ $\mathrm{h}^{-1}(\mathrm{CG})$ resulted in no differences for changes in body mass, serum $\left[\mathrm{Na}^{+}\right]$, POsm, total body water or time required to complete the march. There were no differences between peak exercise core temperature of the $B G\left(38.9^{\circ} \mathrm{C}\right)$ and $C G\left(38.7^{\circ} \mathrm{C}\right)$ groups. There were no differences between the groups for fluid balance, thermoregulation or performance. This is a not a surprising finding since the amount of fluid consumed $a d$ libitum is determined by changes in serum osmolality and not the fluid delivery system as often proposed.
\end{abstract}

Keywords: Water-electrolyte balance; Body temperature regulation; Canteen; Water bladder 


\section{INTRODUCTION}

The extent to which humans need to replace fluid losses during exercise remains contentious despite more than 60 years of focused research $(1,9)$. The debate has special relevance for military populations. Apart from the inherent physiological risk associated with "under-" or "over-" hydration, in providing an excess of water contributes to the burden of the payloads imposed on the dismounted foot soldier $(11,12,13)$.

Commercially available hydration systems (water bladders) consisting of a type of reservoir, delivery tube and bite valve are now frequently advocated for improved hydration and performance in both military and sporting populations alike. A literature review on military hydration by Thomson et al. (17) recommended that the effectiveness and service suitability of "bladder" style water delivery systems should be evaluated. The supposed physiological advantages of such systems include "hands free" hydration, proposing that readily available fluid will encourage soldiers to drink more, therefore improving their "hydration status, keeping them safe" and maintaining their performance. Operationally, soldiers are supposed to benefit from such a method of water delivery since it will allow them to drink without interfering with their primary soldiering tasks (5).

We are aware of only one technical report (5) and one peer reviewed study (4) investigating the possible advantages of such fluid delivery systems compared to traditional military canteens. The first indicated that a bladder type system has operational advantages over traditional canteens but was inconclusive regarding any possible physiological advantages (5). The second study only investigated possible physiological advantages and found that adequate hydration levels were maintained with either a bladder system or traditional canteen. These results did not support the widespread issuing of bladder systems on the premise of improved hydration during basic military training (4). A study by Bishop et al. (2) evaluated the benefits of a bladder type portable hydration system used by workers in encapsulating protective coveralls. The results of their study indicated that hypohydration was effectively mitigated by the use of said system.

Accordingly, the purpose of our study was to assess the possible physiological advantages of bladder hydration systems versus traditional military canteens. In particular, whether such systems indeed result in improved performance and control of total body water (TBW), electrolyte and thermoregulatory responses in exercising soldiers. It was proposed that the amount of fluid consumed during exercise is determined by changes in serum osmolality and not the fluid delivery system, the 
scientific hypothesis tested was: Ad libitum water replacement would not result in any differences for TBW, thermoregulation or performance between groups drinking from either a bladder hydration system or traditional canteen.

\section{METHODS}

\section{Subjects}

Ethical clearance for this study was obtained from the Research Ethics Committee of the South African Military Health Service. Participation was voluntary and all subjects were asked to read and sign an informed consent. All soldiers taking part in an official military exercise were eligible for the study. All subjects had to be medically fit, free from any musculoskeletal conditions and conditioned to carry loads of up to $25 \mathrm{~kg}$ to participate in the study.

\section{Experimental Approach to the problem}

Classification of drinking behaviours of subjects

In order to compare the water delivery systems subjects were randomly assigned to use either the traditional canteen (CG) or a bladder reservoir system (BG). To ensure groups were matched in terms of drinking behaviour, volunteers were asked to indicate their personal preference for fluid intake during exercise from one of the following four statements: 1) I drink as much fluids as I can tolerate; 2) I drink fluids only when I am thirsty; 3) I drink as little fluids as possible; or 4) I drink fluids according to a predetermined schedule (e.g. a certain amount every hour). The results from the drinking preference questionnaire $(\mathrm{N}=100)$ indicated that $46.4 \%$ of the soldiers consumed as much fluid as they can tolerate, $29.9 \%$ indicated that they only consume fluids according to thirst, and $23.7 \%$ of the soldiers preferred to drink fluids to a predetermined schedule. None of the subjects indicated that they drink as little as possible during exercise. These results were used to randomly assign the forty eight soldiers that volunteered for the field experiment to the two water delivery systems. Thus equal numbers of each "type of drinker" were assigned to either the CG or BG. The $C G$ group carried four $2 \mathrm{~L}$ and one $1 \mathrm{~L}$ canteens while the $B G$ group substituted one $2 \mathrm{~L}$ canteen for a $2 \mathrm{~L}$ bladder. This group only drank from the bladder but carried the remaining canteens in order to ensure an equal payload for all subjects. The configuration of a single $2 \mathrm{~L}$ bladder (refilled by canteens) accurately replicates water delivery during active route marches amongst this group of soldiers and therefore allows for comparison between the two groups of subjects. It is noted that future 
similar studies can improve its design by including a cross-over design between the two water delivery systems.

Subject perception of fluid balance before during and after the march

In order to establish the perceptions of the subjects regarding their fluid balance they were asked to answer four questions after completing the route-march. Three questions addressed the perception of their own fluid balance while one question asked their opinion on the assumed link between fluid intake and body temperature during exercise. The four questions were: 1) How do you think you started the route-march in terms of fluid balance? 2) How would you rate your fluid intake during the route-march? 3) How do you think you ended the route-march in terms of fluid balance? 4) Do you think the amount of fluid you drink influences your temperature (how hot you get) during exercise? (E.g. the more fluids you drink the cooler you will stay while the less fluids you drink the hotter you will become).

Route-march and environmental conditions

The exercise intervention was a competitive route-march over $19 \mathrm{~km}$. The payload for each subject was $25 \mathrm{~kg}$. The Wet Bulb Globe Temperature (WBGT) index was recorded during the experiment (WBGT Temperature Measurement System, Questtemp, Quest Technologies, South Africa).

Water intake, route-march time and core temperatures

The only prescription was to consume water ad libitum (as desired) during the march. Subjects did not consume any food during the route march. All canteens and bladders were weighed during and on completion of the march to determine consumption during the exercise period. The time it took for each individual to complete the route-march was recorded. The core body temperature (Tc) of the subjects was recorded with a CorTemp TM2000 (HQ Inc, USA) ambulatory remote sensing system. Tc data were evaluated for the potential confounding effect of fluid ingestion invalidating the ingestible sensor (7). Due to equipment availability only 10 subjects in BG and 11 subjects in the CG were instrumented with Tc recorders. 
Total body water (TBW) and body mass (BM) changes

The diluted isotope technique was used to assess TBW. The accuracy of the deuterium technique closely approximates values measured by desiccation. The total error of measuring TBW with tracer dilution is as low as $1 \%$, thus allowing measurement of fairly small changes in body fluids (15). This technique remains the most reliable method currently available, producing lower coefficient of variation values $(<1 \%)$ than other methods such as bioelectrical impedance (16). A detailed description of the methodology has been published previously $(11,12,13)$. Total body water $(\mathrm{kg})$ was calculated using the preferred method of Halliday and Miller (6). Corrections were made for the ingestion of the isotope dose, metabolic water production and water added to the TBW pool through exchange with atmospheric moisture according to the methods of Schoeller et al (16).

Plasma osmolality (POsm) and serum sodium $\left[\mathrm{Na}^{+}\right]$

Before and after the route-march a blood sample $(5 \mathrm{ml})$ was collected from the antecubital vein to determine POsm and serum $\left[\mathrm{Na}^{+}\right]$concentrations. Subjects were allowed a 45 minute rest and cool down period after completion of the march before the second sample was drawn. This period would ensure that metabolic rates were closer to that of the pre-march level and allow for the return of exercise-induced plasma volume shifts to pre-exercise levels. During this time no food or fluids were allowed.

\section{Statistical Analyses}

Student's T-tests were used to compare results since all the distributions of the paired differences were normal. A Pearson's product-moment correlation coefficient was used to determine relationships between appropriate variables. Statistical significant differences were indicated by a p-value of less than 0.05 .

\section{RESULTS}

\section{Subjects and environmental conditions}

Forty eight subjects volunteered to take part in the study $(B G=27, C G=21)$. The mean age of the subjects was 23.3 and 23.5 years for the $B G$ and the $C G$ respectively. The WBGT index [mean (range)] and relative humidity during the march reached $27.8^{\circ} \mathrm{C}\left(24.2^{\circ} \mathrm{C}-30.1^{\circ} \mathrm{C}\right)$ and $47.7 \%(38.6 \%-56.9 \%)$ respectively. 
Subject perception of fluid balance before during and after the march

Table 1 presents the fluid balance perceptions of the subjects regarding their own fluid balance before, during and after the route-march. It also provides the perception of the subjects regarding the assumed link between fluid intake and Tc during exercise.

Table 1. Subject perception of fluid balance and link between fluid intake and body temperature (\% responses)

\begin{tabular}{|c|c|c|c|c|c|}
\hline Questions & Hyper-hydrated & Dehydrated & Euhydrated & YES & NO \\
\hline $\begin{array}{l}\text { How do you think you started the } \\
\text { route-march? }\end{array}$ & 2.1 & 4.3 & 93.6 & & \\
\hline $\begin{array}{l}\text { How would you rate your fluid intake } \\
\text { during the route-march? }\end{array}$ & 2.1 & 8.5 & 89.4 & & \\
\hline $\begin{array}{l}\text { How do you think you ended the } \\
\text { route-march in terms of fluid balance? }\end{array}$ & 2.1 & 8.5 & 89.4 & & \\
\hline $\begin{array}{l}\text { Do you think the amount of fluid you } \\
\text { drink influences your temperature } \\
\text { during exercise? }\end{array}$ & & & & 72.3 & 27.7 \\
\hline
\end{tabular}


Water intake, route-march time and core temperatures

Table 2 presents the results for the amount of water consumed during exercise, the route-march time as well as the Tc for the instrumented subjects in each of the groups. There were no differences between the $B G$ and $C G$ for water consumption during exercise $[t(45)=-0.31, p>0.05]$. The manner in which the water was available to them also did not result in any difference between the two groups for the time it took to complete the route-march $[\mathrm{t}(45)=-1.37, \mathrm{p}>0.05]$. Similar times indicate similar work rates, and therefore it was not surprising that there were no differences between the respective peak exercise $\mathrm{Tc}$ of the $\mathrm{BG}\left(38.9^{\circ} \mathrm{C}\right)$ and $\mathrm{CG}\left(38.7^{\circ} \mathrm{C}\right)$ groups $[\mathrm{t}(45)=0.06$, $p>0.05]$.

\section{Total body water (TBW) and body mass (BM) changes}

Table 2 presents the changes in TBW and BM during the route-march. Ad libitum water consumption of $538 \mathrm{~mL} \mathrm{~h}^{-1}(B G)$ and $533 \mathrm{~mL} \mathrm{~h}^{-1}$ (CG) resulted in no differences between post exercise TBW [t(45) $=-0.16, p>0.05]$. TBW fell $0.68 \mathrm{~kg}$ and $1.07 \mathrm{~kg}$ for the $B G$ and $C G$ groups respectively $[t(45)=-02.04, p>0.05]$. There was no difference in the amount of BM loss between the two groups $(p>0.05)$. Considering the statistically significant $(p<0.01)$ changes in body mass of $1.80 \mathrm{~kg}(2.5 \%)$ and 1.46 $\mathrm{kg}(1.9 \%)$ for both the BG and CG respectively it is clear that body mass change did not accurately predict changes in TBW as a 1:1 ratio.

\section{Plasma osmolality (POsm) and serum sodium $\left[\mathrm{Na}^{+}\right]$}

Table 2 presents the changes in POsm and serum $\left[\mathrm{Na}^{+}\right]$during the route-march. $\mathrm{Ad}$ libitum water consumption resulted in no differences between post exercise serum $\left[\mathrm{Na}^{+}\right][\mathrm{t}(45)=-1.00, \mathrm{p}>0.05]$ or POsm $[\mathrm{t}(45)=1.27, \mathrm{p}>0.05]$ between the groups. Despite significant $(p<0.01)$ body mass losses of $2.5 \%$ (BG) and $1.9 \%(C G)$, and only replacing water during exercise, serum $\left[\mathrm{Na}^{+}\right]$and $\mathrm{POsm}$ remained unchanged during exercise. 
Table 2. Water intake, route-march time and Tc, TBW, BM, POsm and serum $\left[\mathrm{Na}^{+}\right]$changes during route-march

\begin{tabular}{|c|c|c|c|c|}
\hline & Variable & Minimum & Mean (SD) & Maximum \\
\hline \multirow{19}{*}{$\begin{array}{l}\frac{0}{2} \\
\frac{0}{0} \\
\overline{0} \\
\frac{\overline{0}}{0} \\
\frac{\pi}{0}\end{array}$} & Total water intake $(\mathrm{mL})$ & 0.058 & $1.887(0.777)$ & 3.740 \\
\hline & Hourly water intake $\left(\mathrm{mL} \mathrm{h}^{-1}\right)$ & 0.017 & $0.538(0.206)$ & 1.094 \\
\hline & Route march-time (hh:mm) & $02: 48$ & 03:29 (00:24) & 04:28 \\
\hline & Average core temperature $\left({ }^{\circ} \mathrm{C}\right)$ & 37.7 & $38.3(0.3)$ & 38.9 \\
\hline & Maximum core temperature $\left({ }^{\circ} \mathrm{C}\right)$ & 38.2 & $38.9(0.5)$ & 39.7 \\
\hline & Pre march TBW $(\mathrm{kg})$ & 38.39 & $45.53(5.05)$ & 56.66 \\
\hline & Post march TBW (kg) & 35.76 & $44.85(5.16)$ & 55.39 \\
\hline & Pre march TBW (\% body mass) & 59.13 & $62.93(2.43)$ & 66.59 \\
\hline & Post march TBW (\% body mass) & 58.04 & $63.42(3.19)$ & 67.79 \\
\hline & TBW change $(\mathrm{kg})$ & -2.63 & $-0.68(0.77)$ & 0.58 \\
\hline & TBW change (\% body weight) & -6.85 & $-1.52(1.88)$ & 1.35 \\
\hline & Body mass (Pre march) [kg] & 59.98 & $72.95(7.82)$ & 92.70 \\
\hline & Body mass (Post march) [kg] & 58.48 & $71.14(8.02)$ & 93.36 \\
\hline & Body mass loss $[\mathrm{kg}]$ & -3.04 & $-1.80(0.72)$ & 0.64 \\
\hline & Body mass loss [\%] & -4.1 & $-2.5(0.9)$ & 0.7 \\
\hline & POsm (Pre march) [mosm/kg] & 279.0 & $289.4(6.1)$ & 303.0 \\
\hline & POsm (Post march) [mosm/kg] & 285.0 & $297.4(6.2)$ & 309.0 \\
\hline & $\mathrm{Na}^{+}$(Pre march) $[\mathrm{mmol} / \mathrm{kg}]$ & 137.0 & $138.2(1.1)$ & 140.0 \\
\hline & $\mathrm{Na}^{+}$(Post march) $[\mathrm{mmol} / \mathrm{kg}]$ & 138.0 & $140.4(1.4)$ & 143.0 \\
\hline \multirow{19}{*}{ 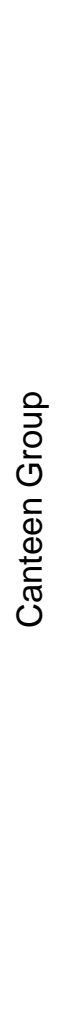 } & Total water intake $(\mathrm{mL})$ & 0.761 & $1.958(0.752)$ & 3.561 \\
\hline & Hourly water intake $\left(\mathrm{mL} \mathrm{h}^{-1}\right)$ & 0.238 & $0.533(0.188)$ & 0.915 \\
\hline & Route march-time (hh:mm) & 03:08 & 03:39 (00:22) & $04: 28$ \\
\hline & Average core temperature $\left({ }^{\circ} \mathrm{C}\right)$ & 38.0 & $38.2(0.2)$ & 38.8 \\
\hline & Maximum core temperature $\left({ }^{\circ} \mathrm{C}\right)$ & 37.0 & $38.7(0.7)$ & 39.6 \\
\hline & Pre march TBW $(\mathrm{kg})$ & 40.75 & $45.85(4.24)$ & 54.69 \\
\hline & Post march TBW (kg) & 39.82 & $44.78(4.29)$ & 53.64 \\
\hline & Pre march TBW (\% body mass) & 59.00 & $61.77(2.55)$ & 66.39 \\
\hline & Post march TBW (\% body mass) & 58.59 & $61.56(2.07)$ & 65.25 \\
\hline & TBW change $(\mathrm{kg})$ & -1.82 & $-1.07(0.46)$ & -0.37 \\
\hline & TBW change (\% body weight) & -4.01 & $-2.35(1.03)$ & -0.75 \\
\hline & Body mass (Pre march) [kg] & 64.98 & $74.90(8.02)$ & 96.52 \\
\hline & Body mass (Post march) [kg] & 63.00 & $73.44(8.02)$ & 95.12 \\
\hline & Body mass loss [kg] & -2.80 & $-1.46(0.66)$ & -0.04 \\
\hline & Body mass loss [\%] & -3.8 & $-1.9(0.6)$ & 0 \\
\hline & POsm (Pre march) [mosm/kg] & 282.0 & $292.9(5.5)$ & 304.0 \\
\hline & POsm (Post march) [mosm/kg] & 284.0 & $294.8(7.0)$ & 305.0 \\
\hline & $\mathrm{Na}^{+}$(Pre march) $[\mathrm{mmol} / \mathrm{kg}]$ & 137.0 & $139.4(1.0)$ & 141.0 \\
\hline & $\mathrm{Na}^{+}$(Post march) [mmol/kg] & 138.0 & $140.8(1.6)$ & 146.0 \\
\hline
\end{tabular}


DISCUSSION

The majority ( $>89 \%$ ) of subjects perceived their own fluid intake pre-, during and post route-march to be representative of a state of euhydration (Table 1). Considering the serum $\left[\mathrm{Na}^{+}\right]$and POsm values presented in Table 2, it is clear that all the subjects indeed both started and ended the route-march in a state of euhydration. Previous findings indicate that ad libitum fluid intake combined with appropriate pacing strategies are sufficient to maintain safe and appropriate thermoregulatory responses under mild (12) and even extreme (13) environmental conditions. It was a concern that only $29.9 \%$ of the subjects indicated that they replace fluids ad libitum during exercise. The majority $(72.3 \%)$ of the subjects furthermore erroneously believed that there was a direct causal relationship between amount of fluid ingested and body temperature during exercise. These findings highlight the need for ongoing educational efforts amongst soldiers and athletes alike regarding safe exercise fluid replacement strategies, exercise associated fluid disturbances and exertional heat illness. Such efforts should highlight temperature regulation during exercise as a complex interaction between fluid replacement, metabolic rate, environmental factors, body composition and clothing configurations.

There were no statistically significant differences $(p>0.05)$ between the two groups for any of the hydration (TBW, POsm, serum $\left[\mathrm{Na}^{+}\right]$), thermoregulation (Tc) or performance (route-march times) markers including the amount of water consumed during exercise. This supports the proposed hypothesis and is not surprising since the amount of fluid consumed ad libitum during exercise is determined by changes in serum osmolality and not the fluid delivery system as is often proposed in product marketing materials.

The results supports previous findings $(11,12,13)$ indicating that changes in BM did not accurately predict changes in TBW as 1:1 ratio and therefore we postulate that BM is not an accurate surrogate for TBW changes during prolonged exercise. Theoretically there are three possible reasons why body mass loss during prolonged exercise may not accurately reflect total body water loss, the first of which is production of metabolic water during fuel oxidation. A second source of water gain is the intake of exogenous water in the form of either water or the water present in food eaten during exercise. A third theoretical source is the release of water with the breakdown of muscle and liver glycogen (13).

There was no relationship for either of the groups between BM loss $(p>0.05)$ or total volume of water consumed $(p>0.05)$ and peak Tc during exercise. This lack of relationship between BM loss and the exercise peak Tc has now frequently been 
reported $(11,12,13)$. The Tc of all the subjects rose and decreased during exercise according to their level of effort determined by their pacing strategies (13) but did not exceed $39^{\circ} \mathrm{C}$ let alone $42^{\circ} \mathrm{C}$; which is considered the danger level for Tc resulting in serious health consequences (3). Instead Tc was regulated within a normal range unrelated to the degree of body mass loss or fluid intake during exercise. The amount of fluid intake during the march was also not related $(p>0.05)$ to the time required to complete the route-march in either of the groups. Accordingly, we conclude that ad libitum fluid intake, irrespective of the type of water delivery system, was sufficient to ensure safe thermoregulation in these subjects who were able to self-regulate their pacing strategies to suit the particular environmental conditions.

Subjects regulated their serum $\left[\mathrm{Na}^{+}\right]$within the normal range while replacing only water during exercise. In both the $B G$ and $C G$ there was a relationship $(p>0.05)$ (negative slope) between post-exercise serum $\left[\mathrm{Na}^{+}\right]$and changes in both TBW and BM. Clearly this indicates that the amount of BM loss in both groups were an appropriate response in order to contribute to the regulation of the serum $\left[\mathrm{Na}^{+}\right]$during the exercise. This indicates that an increase in TBW and BM resulted in a fall in serum $\left[\mathrm{Na}^{+}\right]$, whereas a fall in TBW and BM led to a rise in serum $\left[\mathrm{Na}^{+}\right]$. The data is compatible with previous findings that an increase in BM (and therefore TBW) is the major determinant of exercise-associated hyponatremia $(11,12,13)$. It also confirms a well-established finding that serum sodium concentration can be maintained during exercise without the need for acute sodium replacement during exercise $(7,11,13$,$) ,$ due to serum osmolality and not body mass being the regulated variable both at rest and during exercise. Drinking according to the dictates of thirst would be expected to produce minimal changes in serum osmolality and serum sodium concentration (7).

\section{MILITARY APPLICATIONS}

We conclude that there were no differences in fluid balance, thermoregulation or performance between the groups drinking from either the hands free hydration system or traditional canteen. The amount of fluid consumed ad libitum during exercise will be determined by changes in serum osmolality and not the manner in which the fluid is made available during exercise. It was proposed that the subjects were able to maintain their POsm, serum $\left[\mathrm{Na}^{+}\right]$and safe exercise Tc by: adopting a pacing strategy; ad libitum fluid consumption and a reduction in both body mass and total body water, although not in a 1:1 relationship. 
ACKNOWLEDGEMENTS

Funding: The authors would like to thank the Director Technology Development, Department of Defence, South Africa for the funding of the study. The funder had no involvement on the study design, data collection, analysis and interpretation of data, the writing of the report or the decision to submit the article for publication.

Competing Interest: None of the authors have financial or personal relationships with other people or organisations that could inappropriately influence or bias the content of this paper.

Ethics approval: Ethics approval was provided by the 1 Military Hospital Research Ethics Committee of the South African Military Health Services (SAMHS) of the South African National Defence Force (SANDF).

\section{REFERENCES}

1. Adolph EF and Associates. Physiology of man in the desert. Interscience Publishers. New York, 1947.

2. Bishop PA, Jones EJ, and Green JM. Continuous versus Episodic Hydration in Encapsulating Protective Coveralls. Journal of Occupational and Environmental Hygiene 4: 260-265, 2007.

3. Cheuvront SN, and Haymes EM. Ad libitum fluid intakes and thermoregulatory responses of female distance runners in three environments. Journal of Sports Science 19: 845-854, 2001.

4. Fogt DL, Brosch LC, Dacey DC, Kalns JE, Ketchum NS, Rohrbeck P, Venito MM, Tchandja JB, and Bunning MC. Hydration Status of Air Force Military Basic Trainees After Implementation of the Back-Mounted Hydration System. Military Medicine 174: 821-827, 2009. 
5. Forbes-Ewan CH, Cotter JD, Amos D, and Lau W. Comparison of Two Systems of Water Delivery for Use on Military Operations. DSTO-TR-0787. Defence Food Science Centre. Ship Structures and Materials Division, Aeronautical and Maritime Research Laboratory, Melbourne, Victoria, 1999.

6. Halliday D, and Miller AG. Precise measurement of total body water using trace quantities of deuterium oxide. Biomed.Mass Spectrom 4: 82-7, 1977.

7. Hew-Butler T, Collins M, Bosch A, Sharwood K, Wilson G, Amrstrong M, Jennings C, Swart $\mathrm{J}$, and Noakes T. Maintenance of plasma volume and serum sodium concentration despite body weight loss in Ironman triathletes. Clinical Journal of Sports Medicine 17: 1-7, 2007.

8. Lee JKW, Nio AQX, Lim CL, Teo EY, and Byrne C. Thermoregulation, pacing and fluid balance during mass participation distance running in a warm and humid environment. European Journal of Applied Physiology 109: 887-98, 2010.

9. Noakes TD. Overconsumption of fluids by athletes, British Medical Journal 327:113114, 2003.

10. Noakes TD, Sharwood D, Speedy D, Hew T, Reid S, Dugas J, Almond C, Wharam P, and Weschler L. Three independent biological mechanisms cause exerciseassociated hyponatremia: Evidence from 2,135 weighed competitive athletic performances. In: Proceedings of the National Academy of Sciences USA, 2005. 102: p 18550-18555.

11. Nolte $H$, Noakes TD, and van Vuuren B. Protection of total body water content and absence of hyperthermia despite $2 \%$ body mass loss ("voluntary dehydration") in soldiers 
drinking ad libitum during prolonged exercise in cool environmental conditions. British Journal of Sports Medicine 45: 1106-12, 2010.

12. Nolte H, Noakes TD, and van Vuuren B. Ad libitum Fluid Replacement in Military Personnel during a 4-Hour Route March. Medicine and Science in Sports and Exercise 42: 1675-1680, 2010.

13. Nolte HW, Noakes TD, and van Vuuren B. Trained humans can safely exercise in extreme dry heat when drinking water ad libitum. Journal of Sports Sciences 29: 1233$41,2011$.

14. Nolte HW, Noakes TD, and Nolte K. Ad libitum versus restricted fluid replacement on hydration and performance of military tasks. Aviation, Space and Environmental Medicine 84: 97-103, 2012.

15. Ritz P. Methods of assessing body water and body composition. In: Hydration Throughout Life. Arnaud, M.J. (ed.). Perrier Vittel Water Institute, 63-74, 1998.

16. Schoeller DA, Kushner RF, Taylor P, Dietz WH, and Bandini L. Measurement of total body water. Ross Conference on Medical Research, 1985: 24-29.

17. Thomson GF, Walker GJ, and Forbes-Ewan $\mathrm{CH}$. Review of Methods of Improving the Intake and Absorption of Water into the Body by the Use of Alternative Supply Methods and/or Additives. DSTO-TR-0483. Defence Food Science Centre. Ship Structures and Materials Division, Aeronautical and Maritime Research Laboratory, Melbourne, Victoria, 1997. 